\title{
PROS AND CONS OF USING SOCIAL MEDIA FOR EDUCATIONAL PURPOSES BY HIGHER SECONDARY STUDENTS - CASE STUDY OF THE STUDY SCHOOL, PUDUCHERRY
}

\author{
R. Jayakumar \\ Research Scholar, Department of Library and Information Science, \\ Bharathiar University, Coimbatore, Tamil Nadu, India \\ Head Librarian, The Study L'école Internationale, Puducherry, India \\ N. Tamilselvan \\ Chief Librarian \& Head, RVS College of Engineering and Technology, \\ Coimbatore, Tamilnadu, India
}

\begin{abstract}
Social media (SM) has become a part and parcel of our everyday life that it is very difficult to completely refrain from it. In order to know the positive and negative impact that the social media created on the education of the present day children, a study was conducted. The population of the study were the higher secondary students of a CBSE school in Puducherry. The study revealed various information regarding the SM use by the students and was also a medium to create awareness among the students over the effect of social media on their education. It was found that majority 90 percent of the higher secondary students access social media regularly and the most popular platform was YouTube and WhatsApp which they used for viewing and downloading audio and video and for chatting. Another important finding was that most of the students 98 percent of them believed that social media was useful for their education and 92 percent of them used it for doing assignments and projects, 80 percent to access additional study materials and 74 percent to clarify doubts. The study also revealed the negative impact of SM on the students (48 percent) and many of them felt that they did not get enough study time and could not concentrate on their studies because of using social media with 32 percent and 28 percent respectively. The study also revealed that 72 percent had more virtual friends and 82 percent of them subscribed to entertainment communities compared to 72 percent educational communities.
\end{abstract}

Key words: Social Media, Impact of social media, higher secondary student education, social media for education, negative effect of social media. 
Cite this Article: R. Jayakumar and N. Tamilselvan, Pros and Cons of Using Social Media for Educational Purposes by Higher Secondary Students - Case Study of the Study School, Puducherry. International Journal of Library \& Information Science, 7(1), 2018, pp. 71-81.

http://iaeme.com/Home/issue/IJLIS?Volume=7\&Issue=1

\section{INTRODUCTION}

In the past decade, social media is developing in a turbulent manner and the major adopters of this are the children. They are growing up literally on the social media and its impact is too much that it influences their everyday activities to a vast extent. Social media can either be a boon or bane, it is all in the hands of the users as to how they decide to use it. Children must be inculcated the positive values of social media and also warned about the negative influences that social media can have on them. Awareness must be created at an early age before their addiction becomes irreversible and starts damaging their physical and mental health. After witnessing a series of suicide cases among children because of allegedly playing a viral 'bluewhale' suicidal game, the necessity to monitor the online activities of children has increased manifold. The present study aims to study about the higher secondary students' use of social media in their daily life and how it helps them in education and affects them negatively. This study would be an eye-opener for those children who were until now unaware of the negative consequences of social media and would provide ideas on using the social media positively in their life. This study was conducted in the form of a case study of the standard XII students of The Study L'école International, a popular CBSE school based at Puducherry.

\section{RELATED STUDIES}

A recent study conducted by (McDool, Powell, Roberts, \& Taylor, 2016) on use of social media by the tweens and teens revealed the benefits and risks involved in the same. The positive values of social media included the ability to use social media for connecting with friends and families, provide opportunities to engage in communities which encourages volunteering for various social causes, enhancing creativity by developing and sharing artistic ideas, growth of ideas and vocabulary through blogging, expanding the peer group and connecting with like-minded people for knowledge-sharing, connect with friends forming homework groups, study groups, exchange ideas for assignments and projects, reinforcing language skills, written expression, and many more. They also elaborated on various risk factors in using social media. They included cyber bullying, online harassment, sexting, facebook depression because of lesser likes to their posts, privacy concern, digital footprint, influence of advertising which lead to unnecessary buying activities, and many more. They expressed concern that the children should access only websites that are age-appropriate for them. If a website mentions about age restrictions, the children and parents must follow it. They also set forth various recommendations for paediatricians to educate families about the positive and negative impact of social media on the children and develop interpersonal parentchild relationship that would enable the children to discuss their problems openly with parents and ask guidance.

Another study conducted by (Strasburger \& Hogan, 2013) analysed the impact of social media on the minds of children and adolescents. They compared the positive and negative impact on media over the children's physical and mental health. Revealing that children from the age of 8 to the elder teens spent more than 11 hours on an average over different social media which resulted in lesser study time and lack of sleep, they provided a set of recommendations to parents, teachers and other paediatricians on how to control the online 
Pros and Cons of Using Social Media for Educational Purposes by Higher Secondary Students Case Study of the Study School, Puducherry

activities of the children. According to them, parents do not have any specific rules about time spent on social media which was the major reason for this addiction. Also many children were viewing PG-13 or R-rated movies either online, or on TV or in the theatres which are supposed to be meant only for adult audience. Because of this they come into knowledge about various inappropriate contents which would otherwise be unknown to them. They stressed on the "the positive, prosocial uses of media and the need for media education in schools and at home". Their recommendations for paediatricians included providing ageappropriate counselling for families during every visit and take a highly in-depth media history with problematic children or teenagers especially those who demonstrate aggressive behaviour, are obese, consume drugs or have difficulties at school. They recommended parents to limit the use of entertainment media to less than one hour per day and discourage media ecposure to kids less than two-years age. They also recommended the parents to monitor the internet activities of the children and keep a tab on what type of websites they access. Their recommendation to schools included the need for expansion of media education programs and use of technology like online learning etc to promote positive usage of the social media for educational purposes.

\section{AIM AND OBJECTIVES OF THE STUDY}

The aim of the study is to analyse the positive and negative impact of the use of social media applications on the education of higher secondary students.

The objectives of the study are as follows:

- To identify how many students access social media regularly

- To identify the different type of SM platforms that the students use

- To identify and analyse the primary reason for using social media

- To identify how many students use SM for educational purposes

- To identify the positive impact of SM on education

- To identify the negative impact of SM on the students' education

- To identify the extent to which the students live in a virtual atmosphere comparing to real life.

- To know what type of social media platforms they subscribe to.

\section{METHODOLOGY}

To fulfil the objectives of the study questionnaire was prepared and data were collected through survey method of data collection. The population of the study was higher secondary students of The Study L'école Internationale and out of 200 students, 38\% of total population 76 students were selected through simple random sampling and the response rate was $65.7 \%$, 50 students responded to the survey.

\section{ANALYSIS}

Relevant data were collected through questionnaire and simple analysis was done as necessary.

\subsection{Use of Social Media (SM) Platforms}

Analysis revealed that out of the 50 respondents, 45 of them, 90 percent, use various social media platforms and only 10 percent of the respondents were not engaged in any kind of social media activities (see Fig. 4.1). In an attempt to identify the most used social media platform, it was found that a majority 82 percent of the respondents use You Tube, followed by 70 percent of the respondents using WhatsApp, while 64 percent of them used Instagram, 
58 percent used Google+ and 46 percent used Facebook (see Fig. 4.2). Social media applications like Snapchat, Facebook Messenger were used by 34 percent of the respondents, Pinterest by 30 percent, Twitter and Skype 26 percent, LinkedIn and Slideshare 8 percent, Viber 6 percent and Flickr 4 percent respectively. Thus it was found YouTube and WhatsApp were the most preferred SM applications used by the higher secondary students.

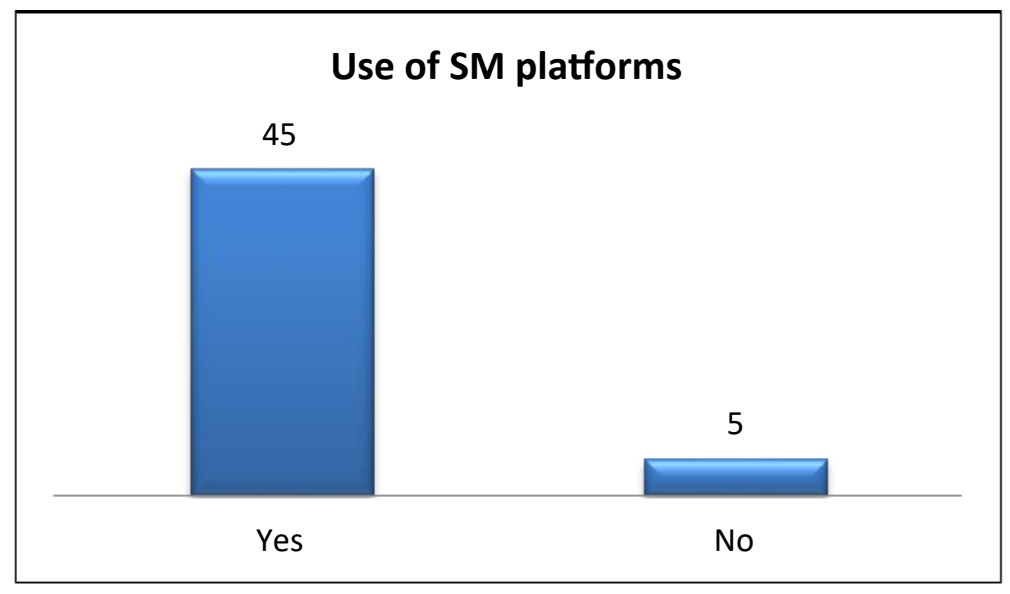

Figure 4.1 Use of social media platforms by students

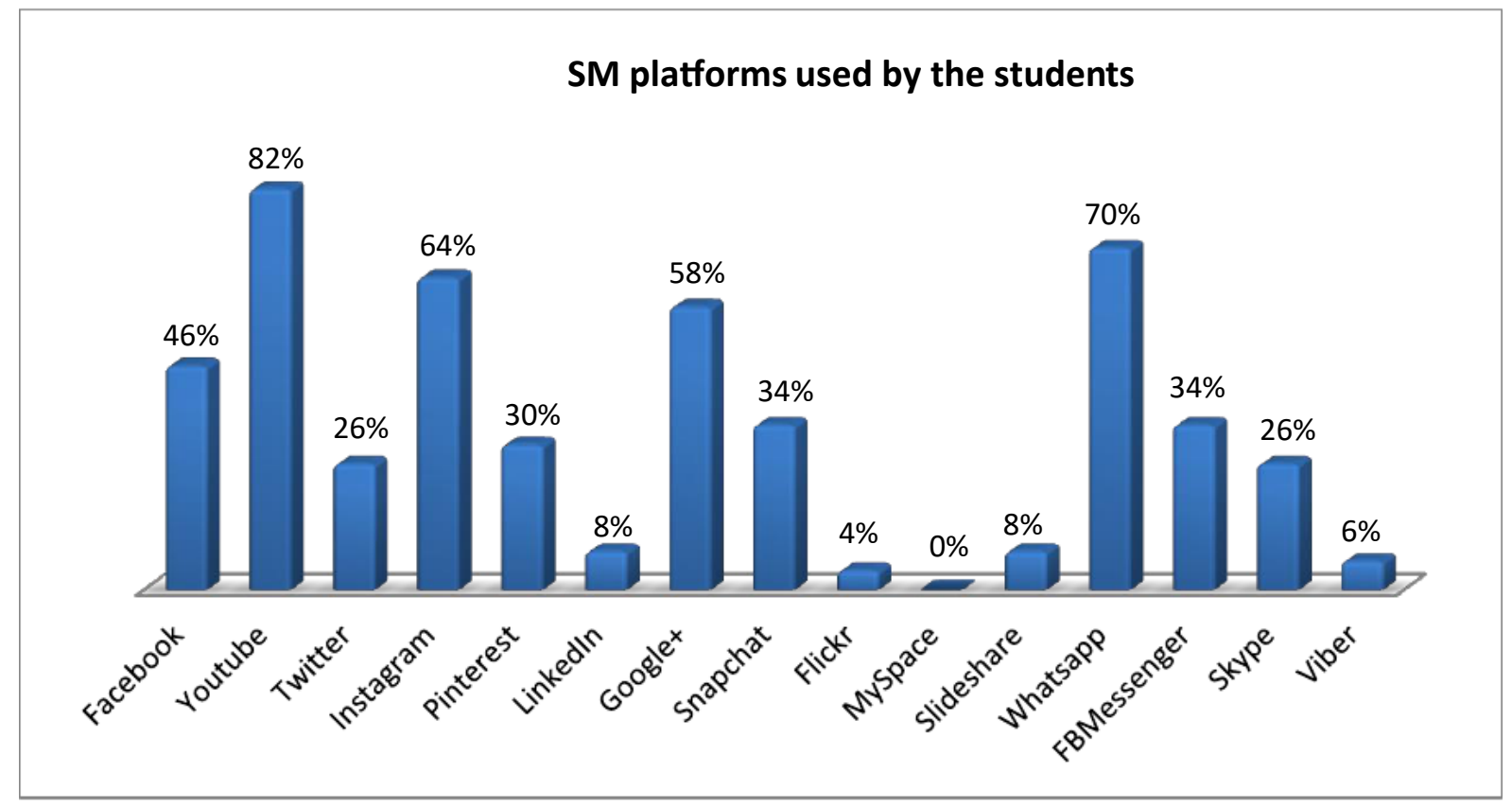

Figure 4.2 Different types of SM platforms used

\subsection{Use of SM Applications to Communicate with Teachers}

While the students were questioned about using the social media platforms to connect with their teachers, 48 percent of them responded that they use the SM platforms to communicate with their teachers while a majority 52 percent of them did not use the SM to communicate with them (see Fig. 4.3). 
Pros and Cons of Using Social Media for Educational Purposes by Higher Secondary Students Case Study of the Study School, Puducherry

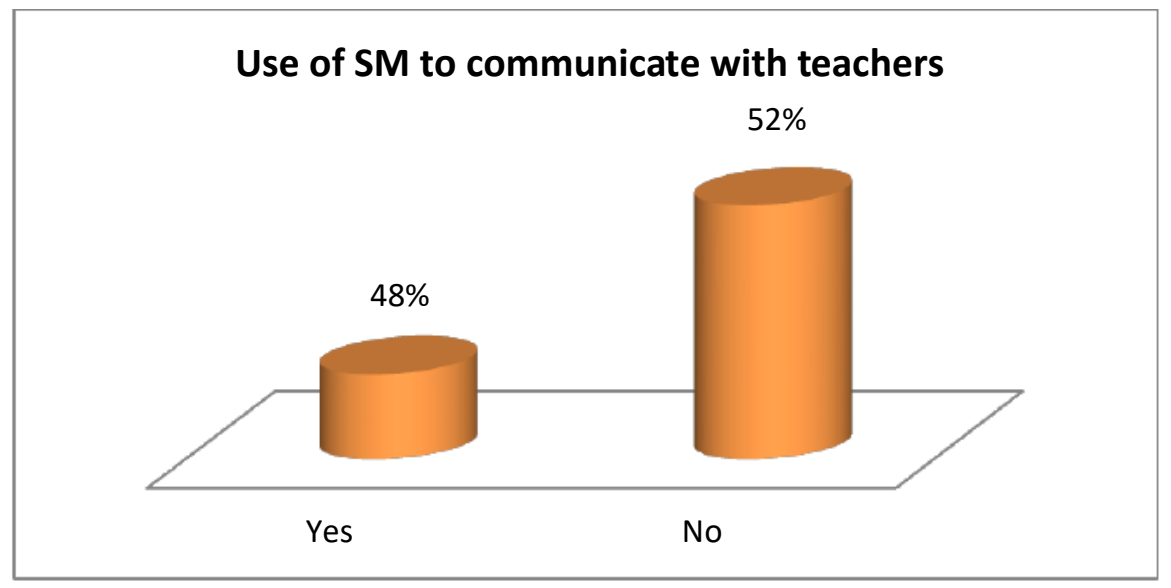

Figure 4.3 Use of social media platforms to communicate with teachers

\subsection{Reasons for using Social Media Applications}

In an attempt to know the primary reason for which the students use social media, various options were given to the respondents and analysis revealed that a majority 74 percent of the students used social media to stream online or download music and videos, and 60 percent of them used social media for general chatting (see Fig. 4.4). 48 percent of the respondents used social media to share photos with others, while 44 percent of them used SM to communicate with their classmates or teachers. Social media apps were used to upload music or video, create online polls and surveys, blogging and contributing to websites by 36 percent, 16 percent, and 14 percents respectively.

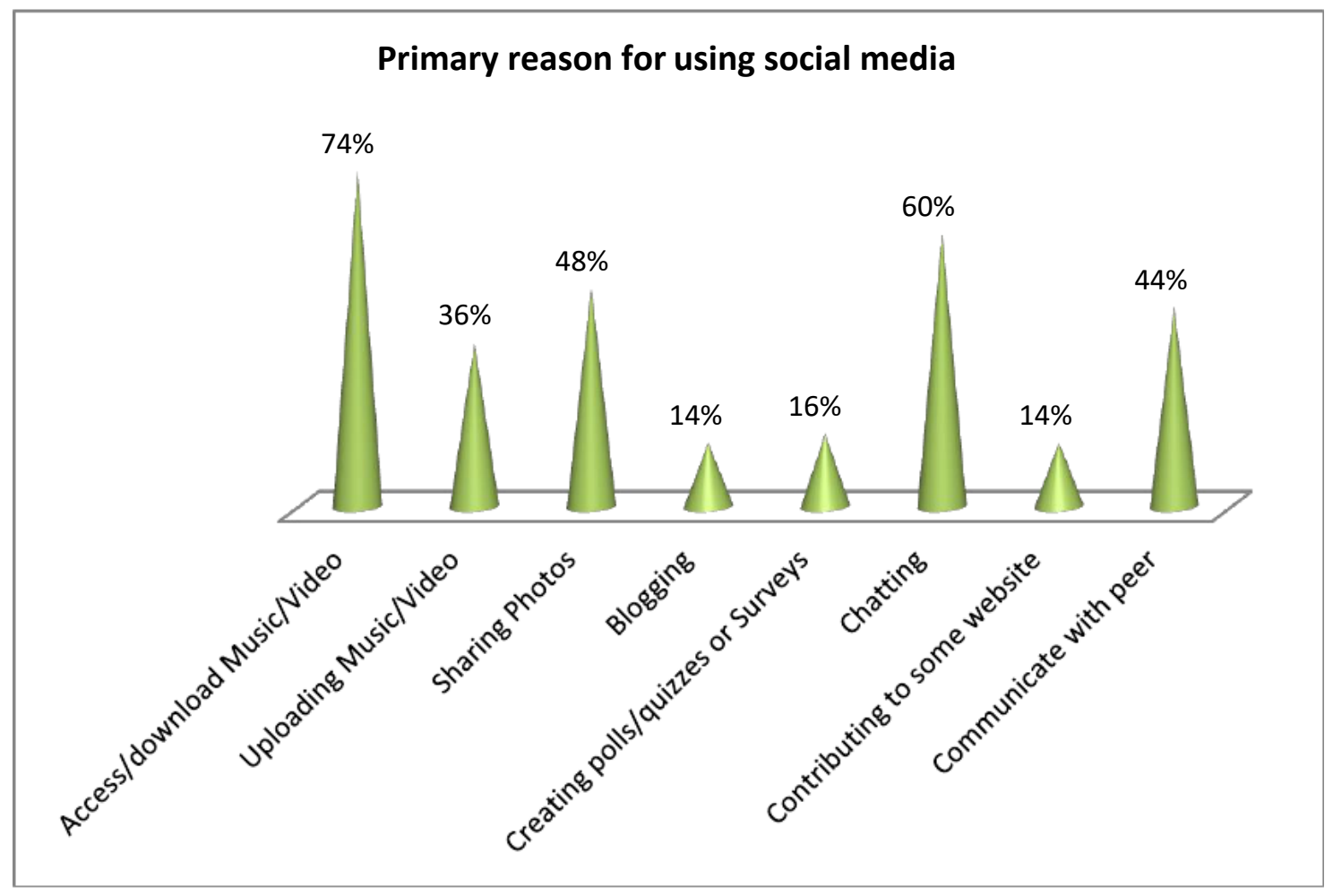

Figure 4.4 Primary reason for using social media platform 


\subsection{Use of Social Media for Educational Purposes}

All the respondents unanimously agreed that they use social media for educational purposes, and 98 percent of them affirmed that social media was really helpful for education but a meagre 2 percent were of the feeling that SM apps did not help in education (see Fig. 4.5 and 4.6).

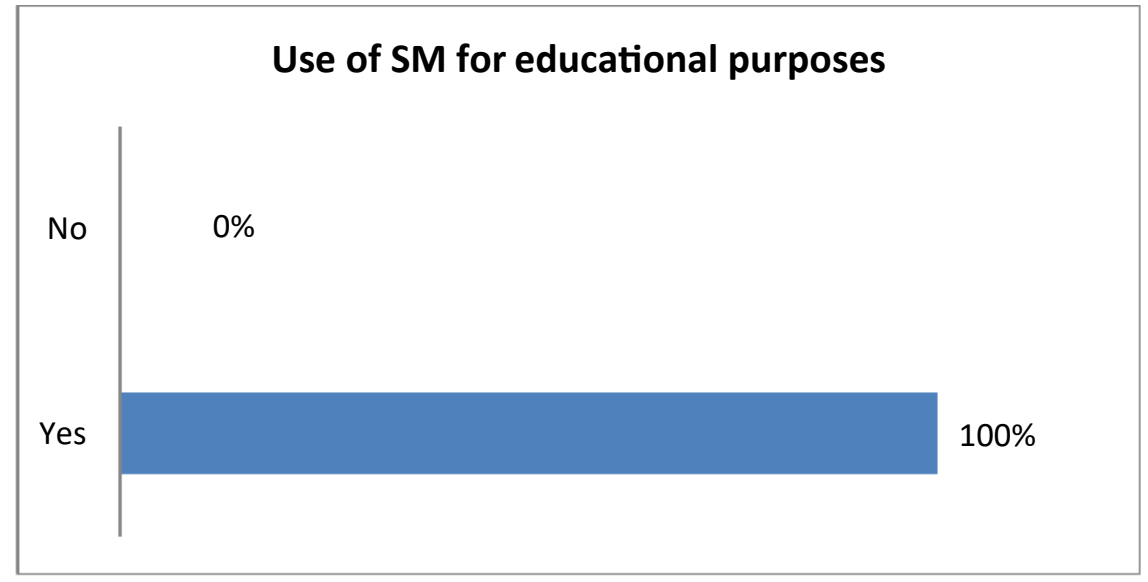

Figure 4.5 Use of Social Media for educational purposes

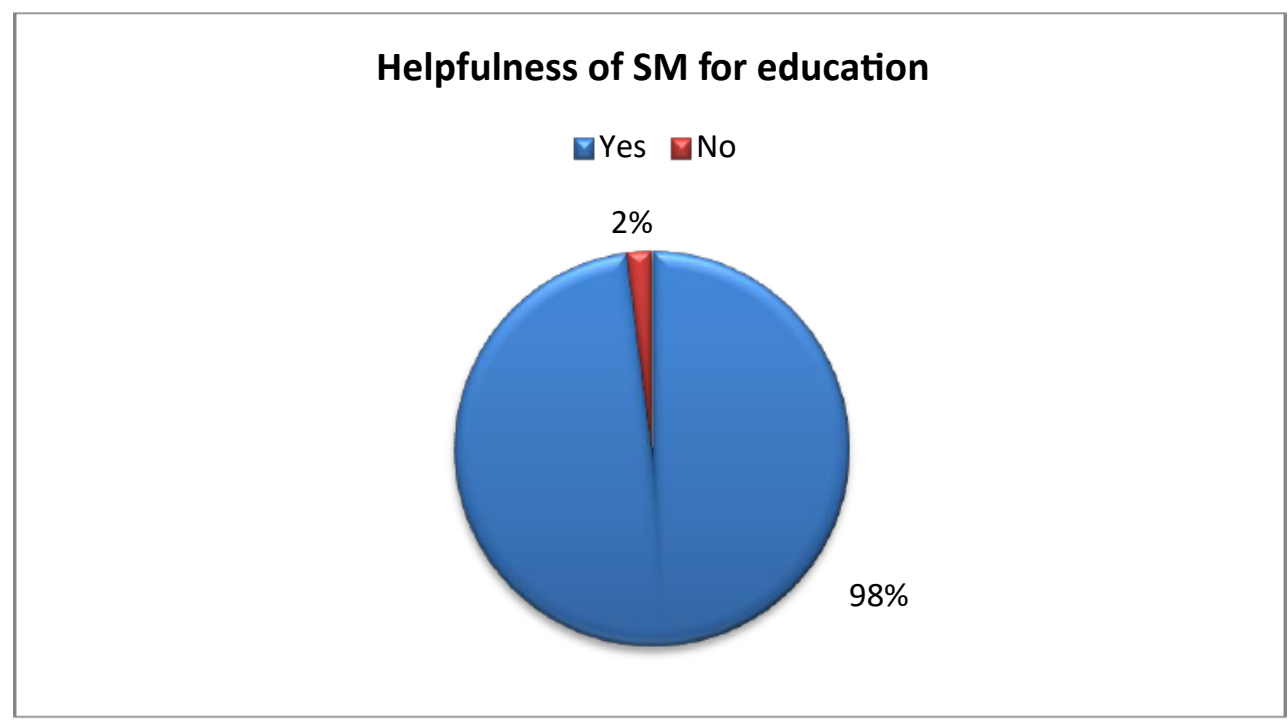

Figure 4.6 Helpfulness of social media for education

Further enquiring to the students as to how the social media was helpful for their education, majority 92 percent of them felt that SM was highly helpful in doing assignments and projects (see Fig. 4.7). They felt that lot of useful information could be accessed with SM apps which would give lot of ideas for their assignments. A major 80 percent of the respondents were able to access additional study materials from the internet, 74 percent of them used SM apps to clarify doubts, 70 percent of them used SM to understand the concepts that they study in school in a better way and 68 percent of them used the SM to share study materials among friends. 
Pros and Cons of Using Social Media for Educational Purposes by Higher Secondary Students Case Study of the Study School, Puducherry

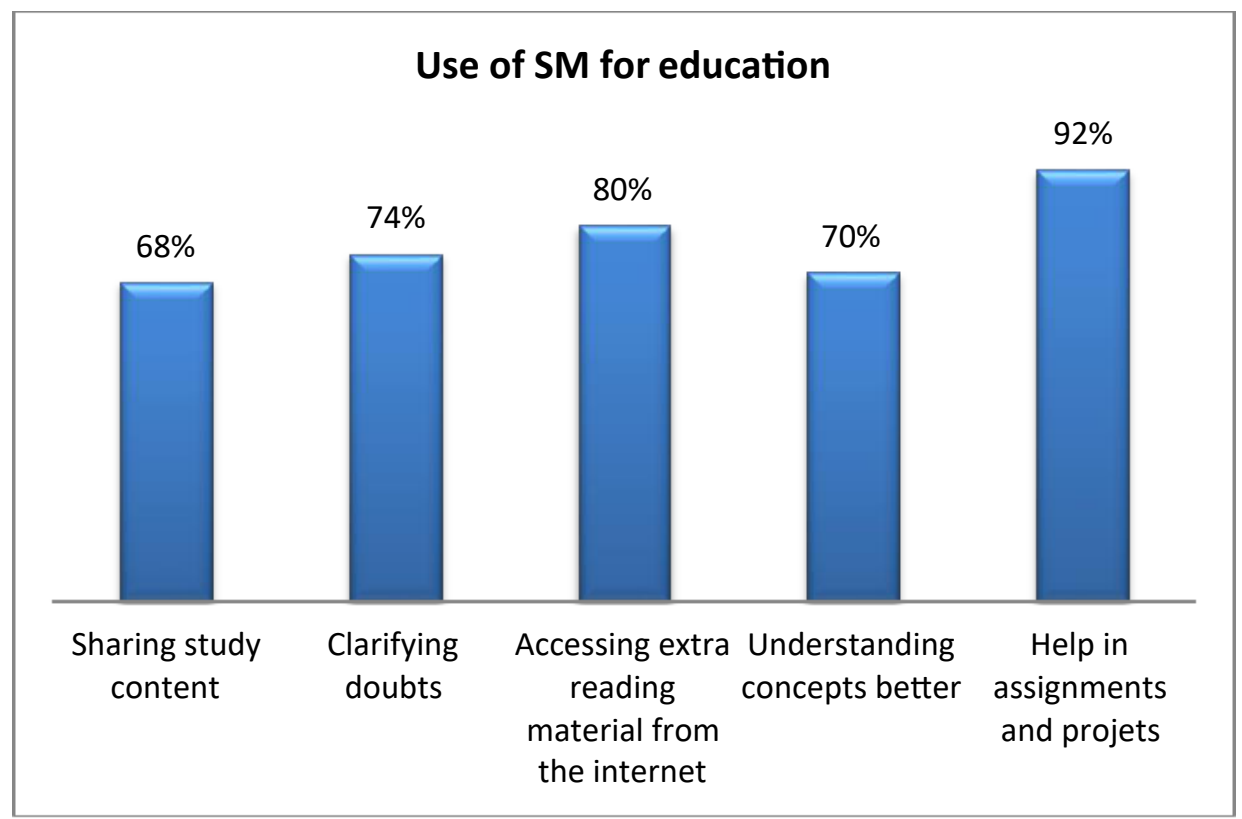

Figure 4.7 Different uses of social media for education

\subsection{Negative Impact of Social Media on Education}

On identifying about the negative role played by the social media in the students' education, more than half of the respondents, 52 percent (see Fig. 4.8) were of the view that social media usage did not affect their studies while 48 percent of them admitted that using SM had a negative effect on their education. Analysis showed that, 32 percent of the respondents felt that using social media reduced their time of studying, and 28 percent of them felt that using SM apps distracted their minds away from studies. 26 percent of them felt that using excessive social media resulted in multi-tasking while studying and 22 percent affirmed that addicting of SM reduced the concentration power while studying (see Fig. 4.9).

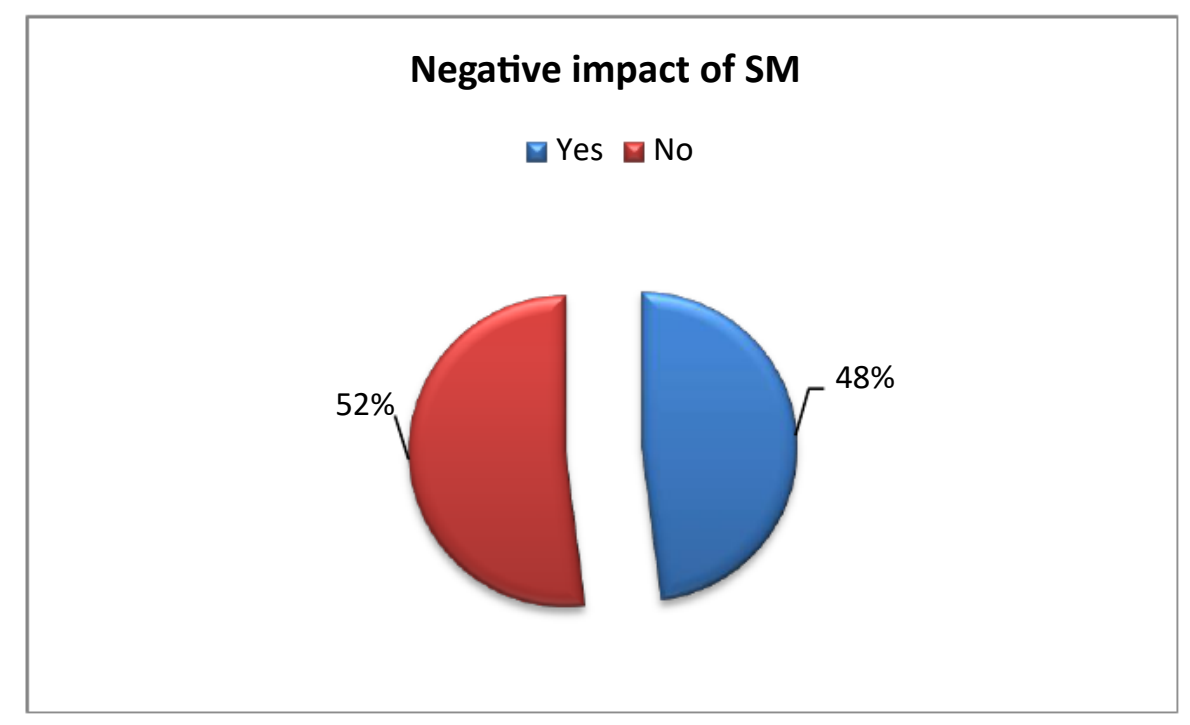

Figure 4.8 Negative impact of social media 


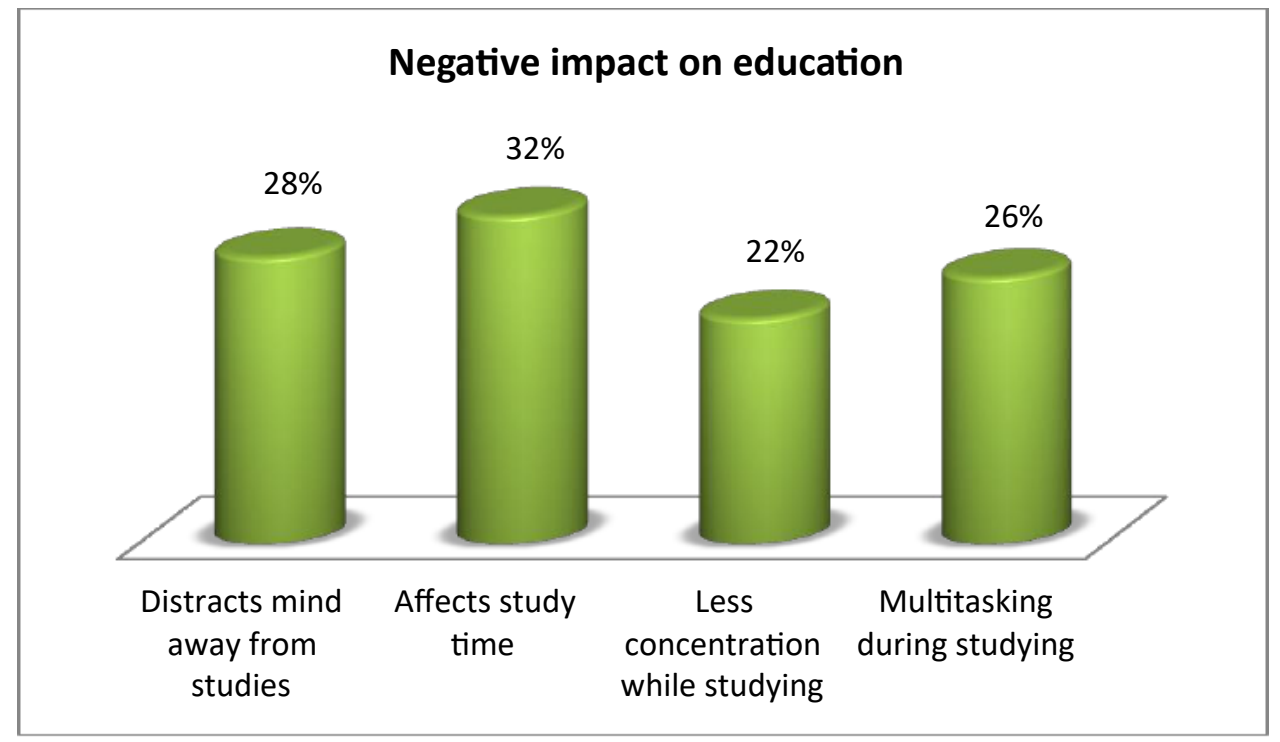

Figure 4.9 Negative impact of social media on education

\subsection{Virtual Living because of Excessive usage of SM}

Social media can be addicting and sometimes lead to multiple personalities of people, where they live in a virtual world on the SM which is totally contrasting from their real life. Study revealed that a major 72 percent of the respondents had more virtual friends via SM platform than real friends and only 28 percent of them had more friends in their real life (see Fig. 4.10). This shows the effect of SM on the personal life of students.

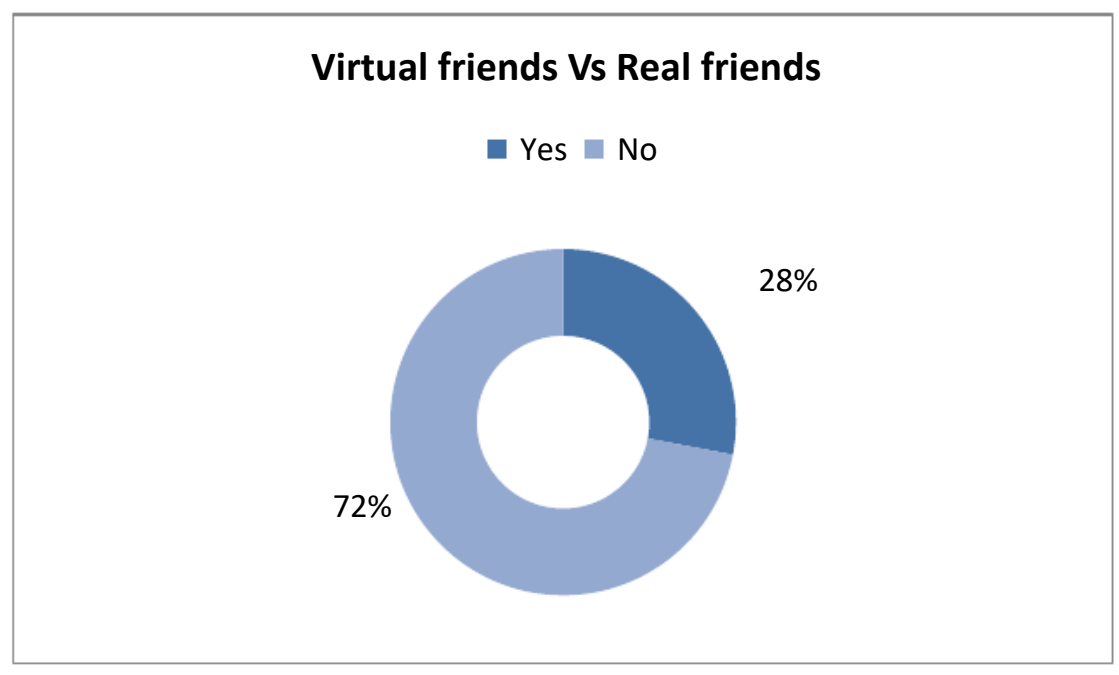

Figure 4.10 More virtual friends when compared to real friends

Virtual living has another impact on the students. Analysis showed that 58 percent of the respondents preferred to express their ideas over the social media than to communicate directly while less than half of them, 42 percent preferred direct communication instead of posting ideas and beliefs over the SM platform (see Fig. 4.11). As a result, most of the respondents had regular subscription over different platforms on the social media. 
Pros and Cons of Using Social Media for Educational Purposes by Higher Secondary Students Case Study of the Study School, Puducherry

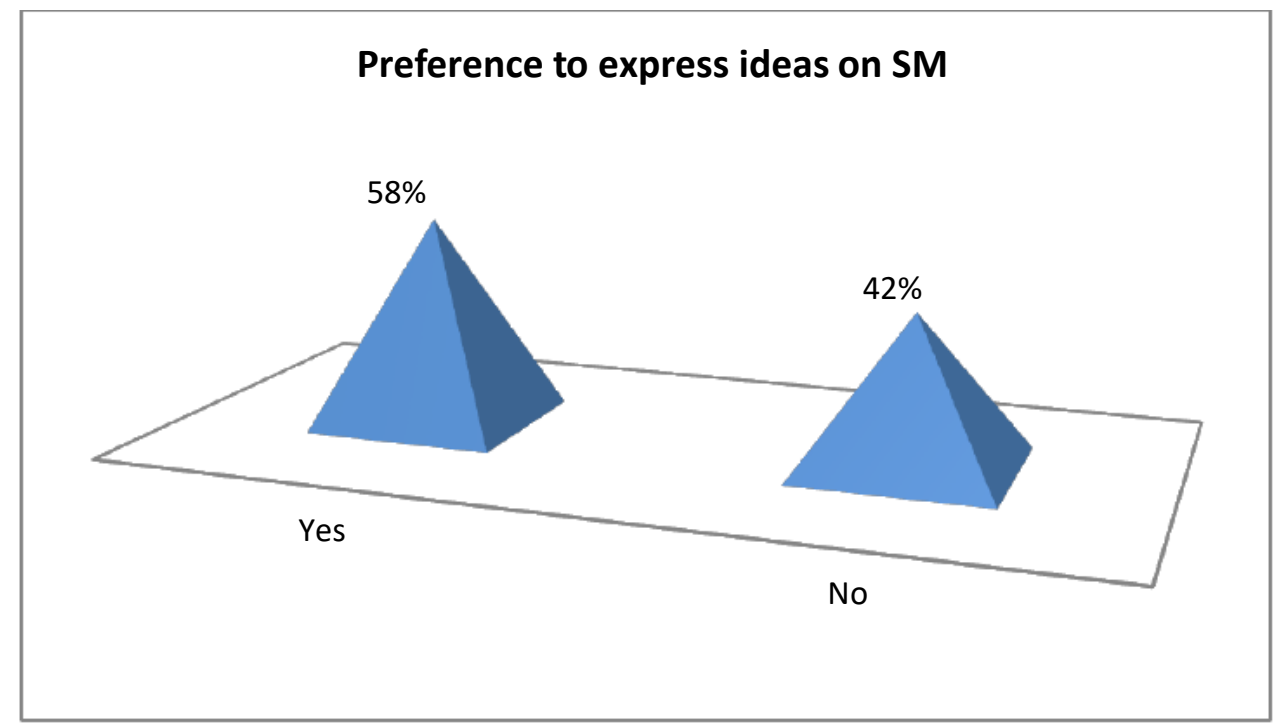

Figure 4.11 Preference to express ideas on social media

A majority 82 percent of the students, subscribed to various entertainment communities on the SM platforms (see Fig. 4.12), while 72 percent of them subscribed to educational communities and 68 percent of them subscribed to informational communities. This showed that students showed more interest in using the social media for entertainment than education.

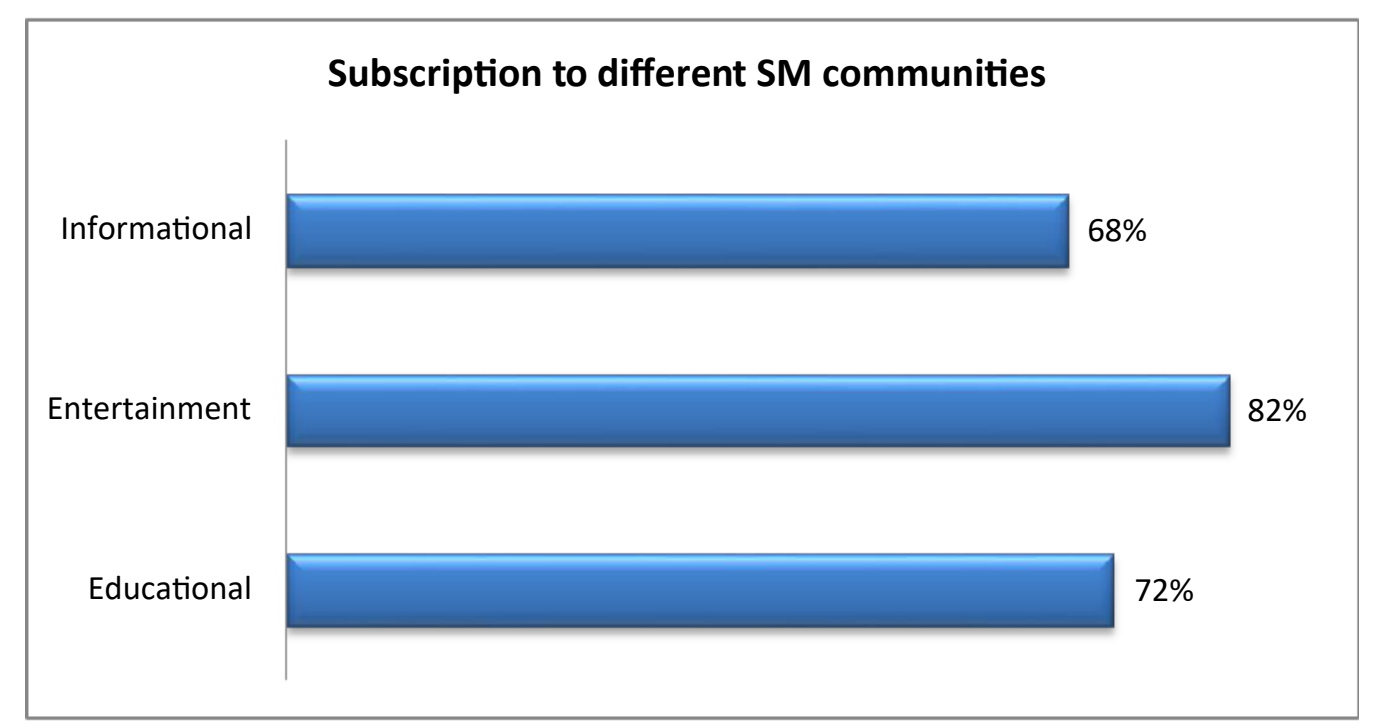

Figure 4.12 Subscription to different social media communities

\section{MAJOR FINDINGS AND DISCUSSIONS}

The major findings of the study conducted are as follows:

- It was found that 90 percent of the respondents use social media regularly. This shows the influence of social media on higher secondary students.

- Out of the various social media platforms available on the internet, it was found that the mostly used social media apps by the higher secondary students was YouTube and WhatsApp with 82 percent and 70 percent respectively.

- Study revealed that majority 52 percent of the students did not use the SM applications for communicate with their teachers. This must actually be encouraged by the teachers so that it 
would be easier to build the teacher-student relationship and students could benefit more for their studies.

- Another finding was that the students use SM platforms maximum for streaming and downloading audio and video files and for chatting with others with 74 percent and 60 percent respectively. This confirms the second finding that they use YouTube and WhatsApp more frequently than other SM apps.

- All of the respondents admitted to using social media for educational purposes while 98 percent of them believed that using SM would actually benefit their studies and 2 percent believed that it would not.

- Findings on how the social media benefitted the educational purposes of the students showed that 92 percent of them used the SM for doing assignments and projects, 80 percent used it to access additional study materials and 74 percent used the SM apps to clarify doubts.

- It was found that 52 percent of the respondents felt that using social media did not have an adverse effect on their studies and considered it to only benefit them while the remaining 48 percent of them admitted that SM had a negative impact on their education.

- Findings on the reason for negative influence of using social media revealed that it reduced their time allotted for studying as 32 percent of the students felt that they spend more time on the social media and had a negative effect on their study-time, and 28 percent were distracted by the SM apps that they could not study for more time.

- The study revealed that a major 72 percent of the respondents had more virtual friends and 58 percent of them preferred to express their ideas in the SM as a result of having too many virtual friends than real-life friends.

- The study also confirmed that majority 82 percent of the students access social media regularly for entertainment purposes as they subscribed to various entertainment communities to keep them updated of the things going on in the entertainment field.

\section{CONCLUSIONS}

From the above conducted study it is clearly seen that most of the higher secondary students access social media on a regular basis but however they use it more for entertainment purposes comparing to educational purposes. Though most of the students agreed that social media is helpful in their education they do not properly utilise the benefits and suffered from negative impacts like addiction and distraction from studies. It is recommended that the educational values of the social media must be inculcated to the students and they must be taught how to streamline their virtual activities and regular daily work. They must be encouraged to use social media for educational purposes than for entertainment and at the same time must be strictly monitored both at school level and at their home as to how they are utilising the social media and benefitting from it.

\section{REFERENCES}

[1] McDool, E., Powell, P., Roberts, J., \& Taylor, K. (2016). Social Media Use and Children's Wellbeing. IZA Institute of Labor Economics Discussion Paper Series No.10412, 1-27.

[2] O'Keeffe, G. S., \& Clarke-Pearson, K. (2011). The Impact of Social Media on Children, Adolescents, and Families. Pediatrics , 127 (4), 800-803. 
Pros and Cons of Using Social Media for Educational Purposes by Higher Secondary Students Case Study of the Study School, Puducherry

[3] Owusu-Acheaw, M., \& Larson, A. G. (2015). Use of Social Media and its Impact on Academic Performance of Tertiary Institution Students: A Study of Students of Koforidua Polytechnic, Ghana. Journal of Education and Practice , 6 (6), 94-101.

[4] Piotrowski, C. (2015). Emerging research on social media use in education: a study of dissertations. Research in Higher Education Journal , 27, 1-12.

[5] Strasburger, V. C., \& Hogan, M. J. (2013). Children, Adolescents, and the Media. Pediatrics , 132 (5), 958-961. 